\title{
Seeking to Deploy Intelligent Transportation Systems: The Surrey County Council Study
}

\author{
Ifechukwu Nnatuanya and John Alexander \\ School of Information Systems, Computing and Mathematics \\ Brunel University, Uxbridge, Middlesex UB8 3PH, U.K.
}

\begin{abstract}
This paper presents a novel, systematic approach to utilizing information systems in solving organizational problems. The paper reports an action research study involving the transportation division of a local government authority in the United Kingdom. Confronted with various transport related problems, these problems are addressed by deploying intelligent transport systems as a core component of a network management and information center. This paper observes the critical success factors for deploying technology within appropriate organizational frameworks. The challenges presented, lessons learned are discussed, and future research directions are considered.
\end{abstract}

\section{KEYWORDS}

intelligent transport systems, Urban Traffic Management and Control (UTMC), organizational strategy, adopting IT

Reprint requests to: Ifechukwu Nnatuanya, e-mail: Ifechukwu.Nnatuanya@brunel. ac.uk; John.Alexander@brunel.ac.uk 


\section{INTRODUCTION}

Over the years, organizations have become increasingly dependent on electronic systems and the information systems that underpin them (Avgerou, 2001; Kendall \& Kendall, 2004). With the growth in the dependence on information systems has also come a change in the way that businesses operate, as well as the mode in which organizations function internally. New models of information systems and the methodologies to create them have been developed to meet the new modes of business requirements (Friedman \& Conford, 1989; Fitzgerald, 1998; Lycett, 1999; Truex et al., 1999). Nevertheless, as the information systems are being designed and implemented within the organizations, the rate at which the effectiveness of the information system diminishes is increasing. The information systems literature argues that this situation is due to the rate of organizational change in modern organizations (Kendall, 1997; Irani, 1999; Irani et al., 2003; Mustonen-Ollila \& Lyttinen, 2004). To this end, organizations are now confronted with the problem of how to deploy an information system effectively in order to support an organizational function.

This paper looks at an approach of applying information systems in solving organizational problems. The paper presents an action research study involving the transportation division of a local government in the United Kingdom (U.K.). Faced with various transport related problems, the deployment of intelligent transport systems is seen as a possible approach to address some of these problems. The paper first describes the problem, then the research approach used for this study, and the objectives are discussed in Sec. 3. These systems are deployed within the framework of a network management and information center, set up to harness all the counties' transportation resources, an approach discussed in Sec. 4. This approach was born out of the introduction of intelligent transportation systems and the adoption of the Urban Traffic Management and Control (UTMC) agenda for local transportation systems. The problems encountered are illustrated, as well as the lessons learned in the case discussed. The paper then summarizes the importance of adopting the right organizational framework alongside the deployment of technology to be a key crucial factor in the success of any intelligent systems (IS) deployment. 


\section{THE PROBLEM}

It is fair to say that information systems development is heavily influenced by organizational strategies and objectives (Checkland \& Holwell, 1998; Avison et al., 2001). This influence is no different in the case of Surrey County Council, a local government authority in the southeast of England. The county is faced with severe road congestion, and one of the objectives set for the council is to address this congestion and bring the level of congestion within the county down to pre-1996 levels. This forms the main thrust of the county councils policy as detailed in Surrey's Local Transportation Plan (LTP) that has led to the proposal to set up a dedicated network management and information center to manage Surrey's transportation portfolio (all county roads as well as highways agency roads and public transportation assets).

Located on the southern tip of London, the Surrey County Council (SCC) is made up of 11 district councils. Each council has a local transportation director who is in charge of the transportation service in that council and works with the county transport division to implement the goals of the county within that council. The office for national statistics has published population estimates for mid 2002. This office has also revised the estimates for 2001 in the light of research into population estimates following the 2001 census (ONS 2001). According to the estimates, the population of Surrey was $1,059,900$ on 30 June 2002, a decrease of 400 since 2001 when compared with the revised estimate for 2001. Natural change (births minus deaths) increased the population by 1,500 but migration and other changes amounted to a decrease of 1,900 . The census estimates that Surrey has one of the highest concentrations of cars owners per household in the U.K.

In terms of its transportation problems, compounding Surrey's high carowner ratio is that it is has one of the busiest commuter routes in the U.K., with four major motorways passing through it (M25, M3, M23, and the A3), which are managed by the U.K. highways agency. Various reports have shown that the second and sixth most congested stretch of road in the U.K. runs through Surrey (BBC, 2003). In addition, Surrey has three large commercial centers (Guildford, Woking, and Epsom) that suffer from traffic congestion, as well as several other major towns and cities that suffer from periodic congestion. All this has added to the urgency of addressing Surrey's 
transport management strategy and has led to the decision to employ technology via the network management and information center.

\section{RESEARCH OBJECTIVE AND APPROACH}

This piece of research used an action research approach for investigating the proposed use and deployment of intelligent transport systems within Surrey County Council. This portion forms part of a wider research project, which also sought to conduct the requirements analysis for the setup of the network management and information center. Taking a consumable view of information systems (Kuljis et al., 2004), it used the Bricolage approach to living information systems development (Nnatuanya, 2005) and implemented the canonical action research model (Davison et al., 2004).

The key characteristics of action research-which were applied in this study and further underpin the reason for selecting this research approachare summarized below and build on the work of Chris Argyris (Argyris et al., 1982)

- Involved a collaborative process between the researcher and practitioners in the problem situation

- Involved a process of critical inquiry

- The focus was on social practice within the organization

- A deliberate focus and process of reflection and learning

For the purposes of this particular part of the study, the method entailed conducting conversational interviews, and interacting with and observing the Network Management and Information Center (NMIC) staff. In addition, the wider organization was surveyed to chronicle the problems they face in their software development in order to aid in the development and testing of a coherent framework for requirements elicitation and analysis and to give some context for the research study.

The IS approach used argues that an organization's view of its IS network would have an impact on how new systems would be implemented and used within it. Using a more modular approach as proposed by the 'consumable' view of an IS would give an organization more flexibility in its 
adoption and implementation of an Information System. Some of the benefits that would be presented by such a system include:

- The ability to adapt the Information System without incurring a huge re engineering cost as the new functionality is gained by adding another Computer System.

- Once a need is redundant in business terms, the Computer System or 'consumable' can easily be removed without a great effect on any of the other computer systems within the IS.

- Such a system can more easily adapt to changing business requirements as brought about by a change in the organization's objectives.

Problems associated with such a system would include the following:

- integration issues-possible problems with integrating computer systems from different suppliers, and

- higher maintenance costs as there could be more divergent computer systems to support within the organization.

For the network management and information center, although the process will have some structure, a flexible/loose design is proposed. This type of design is in adherence with both the UTMC principles of having 'open systems', as well as the Bricolage approach to Living Systems Development, which promotes the idea of a flexible design in which changes to business requirements can be implemented at any time during the IS development.

\section{WHAT ARE INTELLIGENT TRANSPORT SYSTEMS}

Intelligent Transport Systems (ITS) are traffic systems designed and developed to perform more than just an automated traffic function, such as control-traffic systems. The ITS actually involves a more innovative use of other dynamic elements that affect urban and rural traffic (Cheese et al., 1997; Cheese et al., 2002). Building on the case for ITS in traffic management, traffic systems in the U.K. have developed from systems designed just to control the flow of traffic in urban cities (Tate $\&$ Bell, 2002). Traffic systems 
are now being used as tools to manage the entire highway network, including such aspects of travel as car parking (Cheese \& Radia, 2000). Such systems are also used to affect policy objectives, which has arisen partly from an initiative from the department of transport in the U.K. called Urban Traffic Management and Control (UTMC).

\subsection{Urban Traffic Management and Control}

Launched in 1997, the UTMC is the main U.K. Department for Transport (DfT) initiative for the development of a more open approach to Intelligent Transport Systems (ITS) in urban areas. During the first 3 years, a number of research projects were undertaken to establish and validate an approach based on modular systems and open standards. These projects have contributed to the UTMC Technical Specifications, which define UTMC standards.

The UTMC has been driven by a standards body made up of stakeholders in the traffic industry in the U.K. (Cartwright et al., 2002). The stakeholders of this industry are made up of local county councils and district councils through their transportation divisions, equipment manufacturers, and suppliers, as well as the government through the department of transport as the regulator of the industry. The standards body is charged with the responsibility for defining common interfaces and protocols for various intelligent transport systems, such as car park monitoring systems and urban traffic and control systems.

A key element of the UTMC program is to facilitate the continuing development, implementation, and propagation of UTMC principles across all the local government counties in the U.K. To this end, the UTMC Development Group (UDG) of stakeholders, consisting of local authorities and suppliers, has been set up. At the heart of the UTMC protocol sits a common database that acts as the central hub for the Information System. The various computer systems pass data to the common database and can access data from the common database as well, thereby forming a key part of the architecture that enables integration in all UTMC compliant systems.

In January 2001 , the program embarked on its demonstrator phase, which takes the opportunity to consolidate the results of the earlier research. The towns of Preston, Reading, Stratford-upon-Avon, and York are implementing, 
in a pragmatic way, full-scale demonstrator projects based on the UTMC approach. The Surrey County Council seeks to take advantage of this new initiative and deploy a new traffic systems architecture that would enable it to cope with and further improve the traffic situation within the county, given the number of families with cars and the resultant effect on its roads.

\subsection{The Network Management and Information Center}

The Surrey Network Management and Information Center (NMIC) has been set up to bring together a team of people who were formerly functioning as the traffic-signals team in charge of the signals on the Surrey Highway Network. Their designation has now been changed to include a more functional network management role, in addition to their function as the design and operational teams for the traffic signals on the Surrey Highway Network. The vision of the center is to exploit electronic technology to give the Surrey public the best possible transportation service.

Surrey County Council has chosen to adopt the principles of UTMC within their county traffic management systems. The council is building a Network Management and Information Center, through which they plan to introduce various UTMC complaint systems. When implementing new systems, the authority are keen to utilize the vast array of legacy systems in which they have already invested. The reason behind the creation of a Network Management and Information Center is primarily to expand the responsibilities of the traffic signals team from one of maintaining the signals and equipment on a network to one of managing the entire network and having an impact on the public's choice of mode of travel within the county. To achieve this goal, the deployment of several new transport systems has been proposed. The new systems are to be part of a new breed of 'Intelligent Transport Systems'. The duties and functions of a network management team are listed below:

- overall responsibility for the Surrey Highway Network;

- dissemination of relevant traffic and travel information to the general public; and

- management of the traffic flow on the Surrey Network in such a way as to achieve SCC's transportation objectives of less congestion with greater use of public transport. 
TABLE 1

List of transport systems

\begin{tabular}{|l|l|l|}
\hline System & Description & Supplier \\
\hline $\begin{array}{l}\text { Urban traffic and control } \\
\text { (UTC) }\end{array}$ & $\begin{array}{l}\text { Controls signals (traffic } \\
\text { lights) in urban cities }\end{array}$ & Siemens \\
\hline $\begin{array}{l}\text { Real time passenger } \\
\text { information system (RTPI) }\end{array}$ & $\begin{array}{l}\text { Provides real time bus } \\
\text { information }\end{array}$ & ACIS \\
\hline $\begin{array}{l}\text { Remote monitoring system } \\
\text { (RMS) }\end{array}$ & Monitors signals for faults & Siemens \\
\hline $\begin{array}{l}\text { Remote monitoring system } \\
\text { (RMS) }\end{array}$ & Monitors inter city signals & Monitron \\
\hline Car park management system & $\begin{array}{l}\text { Displays live car park } \\
\text { availability in cities }\end{array}$ & Dambach \\
\hline $\begin{array}{l}\text { Variable message signs } \\
\text { (VMS) }\end{array}$ & $\begin{array}{l}\text { Displaying en-route } \\
\text { information }\end{array}$ & New supplier \\
\hline Traffic counters & $\begin{array}{l}\text { Gather statistics on } \\
\text { vehicles }\end{array}$ & Golden River \\
\hline QMISS & Database w. motorway info & Highways Agency \\
\hline
\end{tabular}

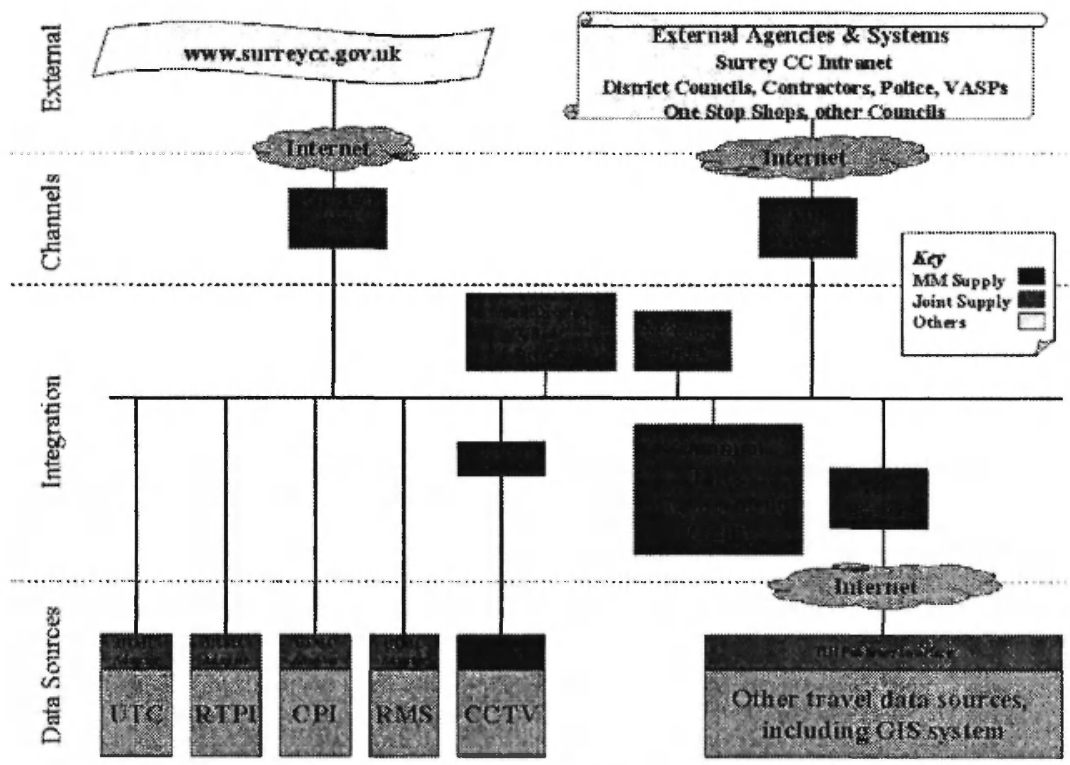

Fig. 1: NMIC System Architecture 
Table 1 lists various transport systems that have specific functions and capabilities. By deciding to adopt UTMC principles within the County's transport management, the authority has been able to integrate these systems via the UTMC common database. This approach has led to an integrated view of the counties transport network (see Fig. 1) and increased their network management abilities. Their legacy systems, such as the UTC and the RMS, have been integrated with newer systems such as the VMS, RTPI, and Traffic Counters. Information is crucial in any Network Management Function as whatever strategies adopted by the center to tackle arising traffic situations have to be based on a 'total picture' to have the desired effect (Cartwright et al., 2002).

\section{ISSUES AND LESSONS}

To define properly an information system to support the center's operations, we had to understand what the center actually does and how it intends to accomplish what it does. This task was achieved by the processes of observation and interviewing some of the stakeholders, as well as reviewing the Local Transportation Plan (LTP) documents and other transportation-related documents within the county.

The analysis of the work being done at the center showed various divergence among the real live operations of the center, what the county council transportation managers and staff of the center testified the center was doing, and what the county council had set out to do based on their documented transportation objectives of how the operations of the center should be carried out (see Table 2). Although the organization had a stated objective (to reduce traffic congestion and to improve transport within the county), and had specified how they intended to achieve this goal (through better traffic management via better technology), the organization did not really have an accurate idea of what they were doing to achieve this. When considering this problem, applying new methods to improve the way the center operated via technology (new transport systems) would not necessarily have taken them closer to achieving their goal.

In addition, there were three distinct opinions as to how the county councils objectives could be met. 
TABLE 2

Snapshot of results ${ }^{1}$

\begin{tabular}{|c|c|c|}
\hline Intention & In-house views & Research findings \\
\hline $\begin{array}{l}\text { Integration-to improve } \\
\text { co-ordination between all } \\
\text { forms of transport }\end{array}$ & $\begin{array}{l}\text { All systems currently in } \\
\text { use are at least partially } \\
\text { integrated }\end{array}$ & $\begin{array}{l}\text { Systems are still being run, } \\
\text { operated and utilized as } \\
\text { isolated systems. The partial } \\
\text { integration is mainly } \\
\text { manual. Also no links to } \\
\text { public transport other than } \\
\text { real time bus information. }\end{array}$ \\
\hline $\begin{array}{l}\text { Integrated Fault Control } \\
\text { Management }\end{array}$ & $\begin{array}{l}\text { Fault data is received } \\
\text { from } 2 \text { sources; UTC and } \\
\text { RMS, and then } \\
\text { consolidated by } \\
\text { PREFECT (this is the } \\
\text { main fault management } \\
\text { system) }\end{array}$ & $\begin{array}{l}\text { Fault data is received from } 3 \\
\text { sources; UTC, RMS and } \\
\text { user input into PREFECT. } \\
\text { It is then consolidated by } \\
\text { PREFECT }\end{array}$ \\
\hline $\begin{array}{l}\text { Provide real time bus } \\
\text { information to the public. } \\
\text { Implement Pegasus system } \\
\text { to reduce school runs } \\
\text { within the county. }\end{array}$ & $\begin{array}{l}\text { Launch ACIS System. } \\
\text { Push this information to } \\
\text { the public and use the } \\
\text { information from bus } \\
\text { running as probe data to } \\
\text { provide additional data } \\
\text { for traffic management }\end{array}$ & $\begin{array}{l}\text { RTPI System being used to } \\
\text { provide real time bus } \\
\text { information to the public. }\end{array}$ \\
\hline $\begin{array}{l}\text { Monitor traffic. Proactively } \\
\text { determine traffic loads, } \\
\text { flow and direction. }\end{array}$ & $\begin{array}{l}\text { Manage traffic using } \\
\text { intelligent bus priority } \\
\text { systems. }\end{array}$ & $\begin{array}{l}\text { Implementing bus priority } \\
\text { systems to actively manage } \\
\text { traffic in favor of buses. }\end{array}$ \\
\hline $\begin{array}{l}\text { Use traffic data to "guide" } \\
\text { the public to public } \\
\text { transport by comparing } \\
\text { public transport times } \\
\text { (including bus, train, } \\
\text { walking \& cycling) with } \\
\text { driving times }\end{array}$ & $\begin{array}{l}\text { Present public with } \\
\text { information on real time } \\
\text { traffic flows to influence } \\
\text { their choice of routes. }\end{array}$ & $\begin{array}{l}\text { No comparisons being done } \\
\text { at the moment. Future plans } \\
\text { for comparisons involve bus } \\
\text { vs. driving times. }\end{array}$ \\
\hline
\end{tabular}

I adapted from Nnatuanya, 2005

The researcher, as part of the team reviewing the operations of the center was able to identify these three distinct views.

1. One set of views was formed by the management team based on targets they were set by the County Council

2. The second set of views was the opinion formed by the traffic engineers 
3. The third perspective was informed by the transport system suppliers who would supply the Computer-Off-The-Shelf (COTS) systems that would be an integral part of the Information System for the Network Management and Information Center

One of the most frequently asked questions in the course of an informationsystems development could potentially be "Did we get the requirements right?" During the evaluation stage of an information system development the analysis is said to be usually based on the set objectives and targets for the specific project that has just been concluded (Nelson et al., 1997; Irani, 2002; Avison \& Fitzgerald, 2003; Kendall \& Kendall, 2004). In this action research study, there were three differing views as to how to achieve those objectives.

To get the best results in the longer term, the value of the traffic engineers to the whole process soon became apparent. Being skilled in the art of traffic control, the engineers possessed more knowledge as to how intervention in a normal traffic system (which would be the end result of better information to the traveling public) could affect traffic flow.

Early on in the study, the project was driven more by the managers who had been charged with the task of "achieving the transportation objectives". Given this fact, the focus was more on doing something that could be easily identified (something tangible that could stand as proof of the problem being addressed). Sometimes the obvious requirement that could be evidence of a problem being addressed would not necessarily have the desired impact in the long run. For instance, giving too much information to the traveling public could be seen to be a good thing but may eventually lead to traffic congestion in a particular part of town that could quickly spread.

As the managers initially drove the requirements definition, however, the result would not necessarily have been ideal. In the final analysis, the views of the traffic engineers are now of primary importance. This situation, however, raises a different point. Now that the 'people' who are in effect deciding the key requirements are those with the understanding of the dynamics surrounding the ideal effect the system should have, is it a risk basing the "organizational information system" on the views of a group of traffic engineers who in this case are the ultimate definers of its requirements? 


\subsection{Particular Issues-Critical Success Factors}

Various issues had a varying degree of impact on this study. Two key issues are presented in this section. Although these issues are not exhaustive, they do give an insight into the sort of challenges that affected this particular study. Some of these issues can be generalized (Lee \& Baskerville, 2003) to other action research studies like the time factor, others (like legislation) are applicable only in research cases with the peculiarities of this study (i.e. areas dependent on government policy).

5.1.1 Organizational politics. The Surrey County Council is currently controlled by the conservative party, which has a relatively wide majority within the county. The profile of the general populace is made up of middleclass families having at least one car within the family. More than 40 percent of homes have at least two cars. Accordingly, traffic congestion is of considerable political importance.

The pressure to deliver from the county councilors had a huge impact on project outcomes in the form of the increased pressure from the transportation directors and managers in seeing quick results from the center. In addition, decisions on the deployment, authorization, and initiation of certain computer systems were constantly being balanced against the wider political agenda.

5.1.2 Legislation. Local county councils in the U.K. are run by a combination of civil servants and elected councilors. The elected councilors, however, normally determine the strategic direction the organization takes. Central government directives and legislation also affect this direction. With this in mind, the Surrey County Council can therefore be described as a political organization.

In terms of transportation policy, local councils usually have to act on central government directives. One such directive involved more financial support to councils that utilize technology to achieve their transportation objectives. The UTMC initiative is one of such initiatives. The central government body that influences transportation policy is the Department of Transport, which actively supports the UTMC initiative.

In this study, two of the biggest risks faced during the course of the requirements-analysis process were the risks of a change in government at both local government and central government levels. A lot of the funding for 
the new intelligent transport systems comes from central government backing for technology schemes that incorporates ideas like the UTMC initiative.

Another factor that would be affected by a change in local government leadership would be the Local Transport Plan (LTP). Within the LTP document are the key targets or objectives that the council has set the network management and information center for Surrey. These objectives and targets are what the current design decisions for the transportation systems and their architecture are based on. Should these objectives change, a possibility exists that the systems in use would also have to be changed.

It can be argued, however, that these changes are anticipated within the system design and that the new systems implementation should be able to be done by substituting systems (see the consumable view of information systems (Kuljis et al., 2004)). The issue that may be disputed though is the value obtained from investing in the information system based on the initial direction the council wanted to take. A typical example would be congestion charging. At the moment, the Surrey County Council is not in favor of using congestion charging to achieve any of their transportation objectives. As such, there is no requirement to incorporate any scope for this in the system architecture. Even though this requirement can be added later, this change will be done at a greater cost than if it were to be included now. Nevertheless, the Council is in favor of increasing the use of bus lanes with automatic bus lane monitoring cameras in town centers, such as Guildford and Woking.

\section{CONCLUSION}

Finally, having reviewed the results of this study, certain deductions can be made that have aided in the successful implementation of the ITS. The first would be the organizational view that Surrey had with respect to the IS infrastructure at the NMIC. In treating the overall development of the NMIC and deployment of ITS as an incremental implementation following on from the consumable view of IS, this approach enabled some built in flexibility in case of any possible changes on the part of the county council leaders. Secondly, the way that requirements are handled and who ultimately determines what the requirements should be can be very crucial in ensuring that the system not 
only does what was intended but also functions effectively, as demonstrated by the traffic engineers input into the process. Finally, this study benefited from being in a field that had an agreed set of standards, which further enables the integration of multiple systems into the network management and information center infrastructure.

One constraint of this study, however, would relate to the knowledge that the study was in a government organization and within an environment that was driven by standards (the traffic industry in the U.K.). Nevertheless, given these constraints, the study could be argued to show that such an approach as that taken in the Surrey case to information systems implementation has a very high chance of being effective. Not only should such an approach prove effective but also it could reduce the speed with which IS deployments decrease in their efficiency and effectiveness over time. Being within the public services and government fields, however, this study was faced with two major challenges - the organizational politics prevalent in local councils and the greater impact on legislative requirements for what in essence is a public service. The flexibility of the consumable view could be argued to have gone some way in ameliorating any of the impacts of these challenges because the cost of deploying new systems or adding new functionality would not be as high as it would otherwise have been due to the modular approach adopted. The same is true in terms of replacing or removing older parts of the system.

In terms of the potential future research directions: one area of research identified would be to study the link between organizational objectives and system requirements. In addition, further work is required to identify their resultant impact on the success or failure of the IS infrastructure and network.

\section{REFERENCES}

Avgerou, C. 2001. The significance of context in information systems and organizational change, Information Systems Journal, 111, 43-63.

Avison, D. and Fitzgerald, G. 2003. Information systems development: methodologies, techniques, and tools, London, UK, McGraw-Hill.

Avison, D., Fitzgerald, G. and Powell, P. 2001. Reflections on information systems practice, education and research: 10 years of the Information 
Systems Journal, Information Systems Journal, 111, 3-22.

British Broadcasting Corporation (BBC). 2003. Congestion Crisis, ht tp:// news.bbc.co.U.K./1/shared/spl/hi/U.K./03/motorwav hotspots/html/defa ult.stm. Accessed $28^{\text {th }}$ February 2005.

Cartwright, M., Radia, B., Thancanamootoo, B. and Tilley, G. 2002. UTMC demonstrators: results so far, Proceedings of the ${ }^{\prime l^{\text {th }}}$ International Conference on Road Transport Information and Control, London, UK, Institution of Electrical Engineers.

Checkland, P. and Holwell, S. 1998. Information, systems and information systems: making sense of the field, Chichester, UK, John Wiley \& Sons.

Cheese, J., Cartw right, M., Routledge, I. and Radia, B. 1997. UTMC research program, Traffic Engineering \& Control, 387/8, 374-375.

Cheese, J.J., Cartwright, M., Routledge, I. and Radia, B. 1998. UTMC - the U.K. initiative for ITS: an update: Results of the first call, progress of the second call, Proceedings of the $9^{\text {th }}$ International Conference on Road Transport Information \& Control, London, UK, IEE, Stevenage, England.

Cheese, J.J. and Radia, B. 2000. UTMC program overview: emerging results, communication standards and the demonstration projects, Proceedings of the Tenth International Conference on Road Transport Information and Control, London, UK.

Davison, R., Martinsons, M.G. and Kock, N. 2004. Principles of canonical action research, Information Systems Journal, 141, 65-86.

Fitzgerald, B. 1998. An empirically-grounded framework for the information systems development process, Proceedings of the International Conference on Information Systems, Helsinki, Finland and Atlanta, Georgia, USA, Association for Information Systems.

Friedman, A.L. and Conford, D.S. 1989. Computer systems development: history, organization and implementation, Chichester, UK, John Wiley \& Sons Ltd.

Irani, Z. 1999. Difficulties of IT/IS investment justification: An interpretivist empirical case study, Proceedings of the $32^{\text {nd }}$ Annual Hawaii International Conference on System Sciences, HICSS-32, Los Alamitos, California, USA, IEEE Comp Soc.

Irani, Z. 2002. Information systems evaluation: navigating through the problem domain, Information and Management, 401, 11-24.

Irani, Z., Themistocleous, M. and Love, P.E.D. 2003. The impact of enterprise application integration on information system lifecycles, Information and Management, 412, 177-187.

Kendall, J.E. 1997. Examining the relationship between computer cartoons and factors in information systems use, success, and failure: visual evidence of met and unmet expectations, ACM SIGMIS Database 282, 113-126.

Kendall, K.E. and Kendall, J.E. 2004. Systems analysis and design, New Jersey, USA, Prentice-Hall.

Kuljis, J., Nnatuanya, I. and Paul, R.J. 2004. Information Systems: assets or 
consumables-growing a path to sustainability, Proceedings of the Tenth Americas Conference on Information Systems, New York, NY, USA, AIS.

Lee, A.S. and Baskerville, R.L. 2003. Generalizing generalizability in information systems research, Information Systems Research, 143, 221-243.

Lycett, M.G. 1999. The development of component based evolutionary information systems, Ph.D. dissertation, Uxbridge, UK, Department of Information Systems and Computing, Brunel University, 204.

Mustonen-Ollila, E. and Lyttinen, K. 2004. How organizations adopt information system process innovations: a longitudinal analysis, European Journal of Information Systems, 131, 35-51.

Nelson, K.M., Nelson, H.J. and Ghods, M. 1997. Technology flexibility: conceptualization, validation, and measurement. Proceedings of the Thirtieth Hawaii International Conference on System Sciences.

Nnatuanya, I. 2005. Evolution of living information systems development. Uxbridge, UK, School of Information Systems, Computing and Mathematics, Brunel University, 154.

Office of National Statistics 2001. 2001 Census reports, www.statistics. gov.U.K./census2001/default.asp. Accessed:November 2004

Truex, D.P., Baskerville, R. and Klein, H. 1999. Growing systems in emergent organizations, Communications of the ACM, 428, 117-123. 